\title{
Mahjong: A routine activity that has chronically harmed the health of land-lost peasants in Southwest China
}

\section{Xiaoyun Xie}

Chongqing Medical University

\section{Yong Zhao}

Chongqing Medical University

\section{Fan Zhang}

Chongqing Medical University

\section{Shu su}

Xi'an Jiaotong University

\section{Nachuan Zhang}

Chongqing Medical University

\section{Ruiyi Liu}

Chongqing Medical University

\section{Zhumin Shi}

\section{Qatar University}

Huan Zeng ( $\nabla$ huanzeng@cqmu.edu.cn )

Chongqing Medical University https://orcid.org/0000-0001-9037-6498

\section{Research article}

Keywords: Mahjong playing behaviors, land-lost peasants, health care, rural-urban migrants, China

Posted Date: April 2nd, 2020

DOI: https://doi.org/10.21203/rs.3.rs-20539/v1

License: (c) (1) This work is licensed under a Creative Commons Attribution 4.0 International License. Read Full License 


\section{Abstract}

Background: Mahjong is a four-player gambling game that originated in China. It is a very popular recreational hobby among land-lost Chinese peasants who have moved to the city due to urbanization. This study aims to identify the influencing factors of Mahjong playing behaviors and their effects on the health of land-lost peasants.

Method: A cross-sectional study was conducted in two districts of Chongqing (Southwest China), which is the first pilot area of the urban-rural integration in China. Researchers recruited 539 land-lost peasants to implement a self-report questionnaire survey. Logistic regression was conducted to identify the key factors associated with Mahjong playing behaviors.

Result: This study found that age is a crucial factor affecting the Mahjong playing behaviors of land-lost peasants. The middle-aged (30-49 years old) and elderly ( $>=50$ years old) are extremely prone to be problematic Mahjong players when compared with young people (18-29 years old). Moreover, people with a high monthly income are more likely to be problematic Mahjong players compared with those with a low monthly income. In addition, the high frequency of playing and long duration of sessions in the enclosed, smoky environment of Mahjong parlors introduce significant hazards to the health of land-lost peasants. However, Mahjong can help them build a social network, provide them with spiritual comfort, and ultimately integrate them into a new environment.

Conclusion: Therefore, we call for measures that can make Mahjong an activity for entertainment rather than gambling and reduce the adverse effects of Mahjong playing behaviors on the players' health.

\section{Background}

At present, urbanization stimulates economic and social developments and is a popular method of modernization. China has been experiencing accelerated urbanization throughout the twenty-first century (Mou et al., 2013). Reports indicate that the proportion of urban residents reached 59\% in 2018 (2018 Revision of World Urbanization Prospects [cited 201820 October].), and the urban population in China is estimated to reach nearly one billion ( $71 \%$ of the total population) by 2030 . The rapid urbanization has given rise to a large number of land-lost peasants across China. Land-lost peasants are defined as individuals who have surrendered their land and moved into a city environment due to urbanization. Land-lost peasants account for a significant portion of the rural-urban migrant population. Chongqing has become the first pilot area for Chinese urban-rural integration. From 2012 to 2020, between 800,000 and 900,000 peasants a year are anticipated to become urban residents (Hong and Ling-yun, 2010). Up to 2015, approximately 277 million people had left their hometown in rural areas to seek job opportunities and pursue better lives in rapidly growing cities (Li and Rose, 2017; Zhong et al., 2018).

Although urbanization is a driving force behind economic and social developments, the process also brings a range of issues. Rural-urban migrants encounter more obstacles than urban residents. In such a large country with great variation in regional geography, culture, and lifestyles, China's internal migrants 
are likely to encounter diverse challenges in adapting to their new environments. Epidemiological research has documented that migration and the urban city contribute to the risks of mental illness, associated with particular features of the urban environment or difficulties encountered in migration ( $\mathrm{Li}$ and Rose, 2017). A study indicated that rural respondents suffered from a significantly higher risk of depression and took less social participation than their urban counterparts(Wang et al. 2019), that would be even worse when they enter a new environment. At the same time, another study also proposed a similar point of view that migrants endure rapid changes in their working and living conditions and weakened family support systems with fragile social support networks. These factors negatively affect their overall well-being $(\mathrm{Li}, 2013)$. In addition, rural-urban migration is considered to be a risk factor for chronic diseases. One Indian study has documented that rural-urban migrants have higher rates of obesity and diabetes than non-migrants (Ebrahim et al., 2010). Besides, the burden of cardiovascular (CV) disease is very high in China, due to highly prevalent and poorly controlled risk factors resulting from changing sociodemographic structure and lifestyles in its large population(Du et al. 2019). According to another study, between 2010 and 2030, Chinese urbanization is projected to raise the rates of agestandardized coronary heart diseases by 73-81 per 100,000 and increase the incidence of stroke from 790.1 to 801.1-830.9 per 100,000 (Mou et al., 2013). Rural-urban migrants experience more mental health problems than urban residents. Common mental health problems are very prevalent among Chinese migrant workers (Zhong et al., 2018), and a study indicated that the mental health of Chongqing rural-urban migrants is remarkably worse than that of the local residents (Mou et al., 2013).

Leisure activities can impact the health of land-lost peasants due to urbanization. Mahjong is a popular gambling game deeply entrenched in Chinese traditions and attracts players across the country (Zheng et al., 2010). A popular belief among the Chinese elderly population states that Mahjong is a means of maintaining one's mental health. Some studies suggest that Mahjong has a positive impact on the cognitive functioning of people with dementia (Cheng et al. 2006,2012; Lee et al. 2018). Studies have also shown that playing Mahjong significantly decreases stress and persistent loneliness among older Chinese (Ross and Zhang 2008; Teh and Tey 2019). However, other researchers found this activity to be associated with increased risks for diabetes mellitus, cardiovascular diseases, and cerebrovascular events. In addition, according to a previous research, the smoking rate in a Mahjong room is as high as 51.33\% (Jin-xiang et al., 2012), exposing many participants to secondhand smoke. Some scholars regard Mahjong as a form of gambling, arguing that players merely use the game as a means to earn "quick money" (Zheng et al., 2010), however, Mahjong often results in the loss of one's hard-earned life savings.

Land-lost peasants moving to a new place may have difficulties in communicating with urban residents and adapting to the city life. These residents encounter many problems, such as social stigmatization, limited social networks, and mental distress. Under such conditions, Mahjong can sometimes be used by land-lost peasants as a coping strategy and a form of socialization(Keovisai and Kim 2019). With the various stressors associated with accelerated urbanization, more land-lost peasants have begun to participate in Mahjong games. 
Mahjong is not only a recreational game, but it has also made problem gambling popular in China. The Mahjong playing behaviors of land-lost peasants in China have rarely been investigated. This crosssectional study aims to identify the key factors of the Mahjong playing behaviors in land-lost peasants by focusing on Chongqing, Southwest China. The authors aim to provide a useful strategy for improving the health of land-lost peasants throughout China.

\section{Methods}

\section{Study setting}

A cross-sectional study was conducted in Shapingba and Bishan districts of Chongqing from July 15 to 26,2013 . Two resettlement residential communities were randomly selected among 149 communities in the two districts. A resettlement residential community is a place where the government has built homes to address the housing issue of the land-lost peasants.

\section{Study population}

This study included land-lost peasants who were aged 18 years or older and living in the community. Land-lost peasants are defined as those who have lost their land holdings according to the law within the last five years. The participants were recruited from the randomly selected communities using convenience sampling methods and required to complete a two-part questionnaire.

\section{Self-completed questionnaire}

The questionnaire is comprised of nine questions on background data, such as gender, age, and monthly income; 12 questions on Mahjong playing behaviors, including Mahjong playing frequency, bet for Mahjong gambling, smoking situation, and impact of playing Mahjong (positive and negative effects); and 11 questions on health conditions. The questionnaire survey was conducted in the parks or squares of resettlement residential areas, where land-lost peasants often gather together. The participants completed a paper survey after being interviewed by the researchers. Upon completion of the investigation, each participant was provided with a small gift as an incentive. A pilot study was conducted prior to the survey to test and refine the questionnaire.

\section{Quality assurance}

The questionnaire was developed through a comprehensive literature review and refined after the pilot study. The investigators were experienced in the related research fields and received professional training (including training on investigational methods and quality control measures) prior to participating in this study. To ensure high-quality data collection, the research team examined the questionnaires daily during the whole study period to correct any logical mistakes and to double-check the transcriptions of the data through EpiData 3.0.

\section{Definition of occasional and problematic player}


In accordance with the data on Mahjong playing behaviors derived from the self-completed questionnaires, the participants in this study were classified into three categories. "Non-players" refer to those who do not play Mahjong at all. "Occasional players" have all the following characteristics:

Mahjong playing frequency is less than three times a week, duration of each time is less than six hours, have not been quarreling with family members due to Mahjong, and betting is less than 10 RMB.

"Problematic players" have one of the following characteristics: Mahjong frequency is more than three times a week, duration of each time is more than six hours; have been quarreling with family members due to Mahjong, and betting is more than $10 \mathrm{RMB}$. The problematic players are more likely to suffer some adverse effects due to Mahjong. Sex, age, current marital status, highest educational attainment, and monthly income were also included in the analysis.

\section{Data analysis}

The questionnaires were transcribed using EpiData 3.0, and data analysis was carried out using Stata (version 13, StataCorp, College Station, TX). Chi-square tests were used to compare differences in the categorical variables. The association between sociodemographic factors and Mahjong playing status was analyzed using logistic regression models or multinominal logistic regression depending on the outcome variables (binary or more than binary), adjusting for multiple covariates. The multivariable models controlled for gender, age (continuous), education, marriage, and income.

\section{Ethical approval}

The study was reviewed and approved by the Institutional Review Board of Chongqing Medical University. All participants provided verbal consent, participating in this study was associated with minimal risk, and non-biological samples were collected. 
Table 1

Mahjong participation, demographic and social characteristics of land-lost peasants in Chongqing, Southwest of China, 2013

\begin{tabular}{|c|c|c|c|c|c|}
\hline Characteristics & Total(\%) & $\begin{array}{l}\text { Play } \\
\text { Mahjong(\%) }\end{array}$ & $\begin{array}{l}\text { Not play } \\
\text { Mahjong(\%) }\end{array}$ & $\begin{array}{l}\text { Chi-2 } \\
\text { value }\end{array}$ & $\begin{array}{l}P \\
\text { value }\end{array}$ \\
\hline Gender & & & & 1.159 & 0.282 \\
\hline Male & $223(41.4)$ & $68(30.5)$ & $155(69.5)$ & & \\
\hline Female & $316(58.6)$ & $83(26.3)$ & 233(73.7) & & \\
\hline Age & & & & 7.940 & 0.019 \\
\hline $18-29$ yrs & $88(16.3)$ & $19(21.6)$ & $69(78.4)$ & & \\
\hline $30-49$ yrs & $248(46.0)$ & 84(33.9) & 164(66.1) & & \\
\hline$\geq 50$ yrs & 203(37.7) & $48(23.7)$ & 155(76.3) & & \\
\hline Education & & & & 5.317 & 0.070 \\
\hline Elementary or below & $228(42.3)$ & $52(22.8)$ & 176(77.2) & & \\
\hline Junior and senior high & $254(47.1)$ & 81(31.9) & $173(68.1)$ & & \\
\hline College or above & $57(10.6)$ & 18(31.6) & $39(68.4)$ & & \\
\hline Current marital status & & & & 0.023 & 0.989 \\
\hline Not married & $48(8.9)$ & $13(27.1)$ & $35(72.9)$ & & \\
\hline Married & $466(86.5)$ & $131(28.1)$ & 335(71.9) & & \\
\hline Divorced or widowed & $25(4.6)$ & $7(28.0)$ & 18(72.0) & & \\
\hline $\begin{array}{l}\text { Number of those who live together } \\
\text { with participants }\end{array}$ & & & & 0.037 & 0.982 \\
\hline 1 & $24(4.5)$ & $7(29.2)$ & 17(70.8) & & \\
\hline 2 & $48(8.9)$ & $13(27.1)$ & $35(72.9)$ & & \\
\hline$\geq 3$ & $467(86.6)$ & $131(28.1)$ & $336(71.9)$ & & \\
\hline Monthly income(RMB) & & & & 14.455 & 0.006 \\
\hline$<1000$ & $26(4.8)$ & $7(26.9)$ & 19(73.1) & & \\
\hline $1000-4999$ & $266(49.3)$ & $72(27.1)$ & 194(72.9) & & \\
\hline 5000-9999 & $112(20.8)$ & $36(32.1)$ & $76(67.9)$ & & \\
\hline$\geq 10000$ & $36(6.7)$ & $18(50.0)$ & $18(50.0)$ & & \\
\hline
\end{tabular}




\begin{tabular}{|llllll|}
\hline Characteristics & Total(\%) & $\begin{array}{l}\text { Play } \\
\text { Mahjong(\%) }\end{array}$ & $\begin{array}{l}\text { Not play } \\
\text { Mahjong(\%) }\end{array}$ & $\begin{array}{l}\text { Chi-2 } \\
\text { value }\end{array}$ & $\begin{array}{l}\text { P } \\
\text { value }\end{array}$ \\
\hline Not clear & $99(18.4)$ & $18(18.2)$ & $81(81.8)$ & \\
\hline
\end{tabular}


Table 2

The characteristics of Mahjong behavior of the land-lost peasants in Chongqing, Southwest of China, $2013(n=151)$

\begin{tabular}{|c|c|}
\hline Mahjong behavior & $n(\%)$ \\
\hline \multicolumn{2}{|l|}{ Frequency } \\
\hline Less than once per week & $42(27.8)$ \\
\hline Once to three times per week & $67(44.4)$ \\
\hline More than three times per week & $42(27.8)$ \\
\hline \multicolumn{2}{|l|}{ Duration each time } \\
\hline$<3 \mathrm{~h}$ & $25(16.6)$ \\
\hline $3-6 h$ & 118(78.1) \\
\hline$>6 \mathrm{~h}$ & $8(5.3)$ \\
\hline \multicolumn{2}{|l|}{ Jetton(RMB) } \\
\hline None & $5(3.3)$ \\
\hline$<5$ & $57(37.7)$ \\
\hline $5-10$ & $78(51.7)$ \\
\hline$>10$ & $11(7.3)$ \\
\hline \multicolumn{2}{|l|}{ Place } \\
\hline Your house/your friend's house & $34(22.5)$ \\
\hline Mahjong parlor & $85(56.3)$ \\
\hline Teahouse and other places & $32(21.2)$ \\
\hline \multicolumn{2}{|l|}{ Dining place when playing Mahjong } \\
\hline Your house or your friend's house & 136(90.1) \\
\hline Mahjong parlor, teahouse, restaurant, ordering takeout and so on & $15(9.9)$ \\
\hline \multicolumn{2}{|l|}{ Do you dine regularly when playing Mahjong? } \\
\hline Yes & 145(96.0) \\
\hline No & $6(4.0)$ \\
\hline \multicolumn{2}{|l|}{ Is there someone smoking when playing Mahjong? } \\
\hline Yes & $132(87.4)$ \\
\hline
\end{tabular}




\begin{tabular}{|ll|}
\hline Mahjong behavior & $\mathrm{n}(\%)$ \\
\hline No & $19(12.6)$ \\
\hline Have you ever had some physical discomfort after playing Mahjong? & \\
\hline Yes & $39(25.8)$ \\
\hline No & $112(74.2)$ \\
\hline Impact of playing Mahjong (multiple choices) & \\
\hline Mental exercise & $23(15.1)$ \\
\hline Increasing income & $19(12.5)$ \\
\hline Making friendly contacts & $49(32.2)$ \\
\hline Eliminating negative emotions & $37(24.3)$ \\
\hline Removing troubles & $24(15.8)$ \\
\hline Have you ever had a quarrel with your family on playing Mahjong? & \\
\hline Yes & $35(23.2)$ \\
\hline No & $116(76.8)$ \\
\hline
\end{tabular}


Table 3

Sociodemographic factors associated with mahjong play status (reference: none player); relative risk ratios and $95 \% \mathrm{Cl}$ in unadjusted and adjusted using multinominal logistic regression.

\begin{tabular}{|c|c|c|c|c|}
\hline & \multicolumn{2}{|c|}{ Occasional player } & \multicolumn{2}{|c|}{ Problematic player } \\
\hline & Model $1^{\mathrm{a}}$ & Model $2^{b}$ & Model $1^{\mathrm{a}}$ & Model $2^{b}$ \\
\hline \multicolumn{5}{|l|}{ Gender } \\
\hline Men & 1 & 1 & 1 & 1 \\
\hline Women & $\begin{array}{l}0.966(0.585- \\
1.592)\end{array}$ & $\begin{array}{l}0.973(0.577- \\
1.640)\end{array}$ & $\begin{array}{l}0.683(0.415- \\
1.122)\end{array}$ & $\begin{array}{l}0.807(0.480- \\
1.357)\end{array}$ \\
\hline \multicolumn{5}{|l|}{ Age } \\
\hline $18-29$ yrs & 1 & 1 & 1 & 1 \\
\hline $30-49$ yrs & $\begin{array}{l}1.262(0.647- \\
2.459)\end{array}$ & $\begin{array}{l}1.855(0.751- \\
4.578)\end{array}$ & $\begin{array}{l}3.534(1.341- \\
9.313)\end{array}$ & $\begin{array}{l}5.782(1.589- \\
21.038)\end{array}$ \\
\hline$>=50 y r s$ & $\begin{array}{l}0.635(0.303- \\
1.332)\end{array}$ & $\begin{array}{l}1.169(0.417- \\
3.276)\end{array}$ & $\begin{array}{l}2.492(0.923- \\
6.728)\end{array}$ & $\begin{array}{l}5.036(1.265- \\
20.054)\end{array}$ \\
\hline \multicolumn{5}{|l|}{ Education } \\
\hline Low & 1 & 1 & 1 & 1 \\
\hline $\begin{array}{l}\text { Junior \& senior } \\
\text { high }\end{array}$ & $\begin{array}{l}1.901(1.099- \\
3.290)\end{array}$ & $\begin{array}{l}1.729(0.951- \\
3.143)\end{array}$ & $\begin{array}{l}1.333(0.787- \\
2.258)\end{array}$ & $\begin{array}{l}1.453(0.818- \\
2.581)\end{array}$ \\
\hline College or above & $\begin{array}{l}1.962(0.865- \\
4.452)\end{array}$ & $\begin{array}{l}1.761(0.679- \\
4.567)\end{array}$ & $\begin{array}{l}1.245(0.529- \\
2.391)\end{array}$ & $\begin{array}{l}1.476(0.556- \\
3.922)\end{array}$ \\
\hline \multicolumn{5}{|l|}{ Marriage } \\
\hline Unmarried & 1 & 1 & 1 & 1 \\
\hline Married & $\begin{array}{l}0.755(0.346- \\
1.645)\end{array}$ & $\begin{array}{l}0.630(0.211- \\
1.882)\end{array}$ & $\begin{array}{l}1.724(0.593- \\
5.014)\end{array}$ & $\begin{array}{l}0.515(0.120- \\
2.261)\end{array}$ \\
\hline Others & $\begin{array}{l}0.432(0.084- \\
2.215)\end{array}$ & $\begin{array}{l}0.467(0.725- \\
3.008)\end{array}$ & $\begin{array}{l}2.431(0.580- \\
10.181)\end{array}$ & $\begin{array}{l}0.860(0.144- \\
5.141)\end{array}$ \\
\hline \multicolumn{5}{|l|}{ Income* } \\
\hline Low & 1 & 1 & 1 & 1 \\
\hline
\end{tabular}

a Model1 unadjusted

b Model2 adjusted for all the variables in the table

* Income: "Low" means less than 4999 RMB; "Medium" means between 5000 to 9999 RMB; "High" means more than 10000 RMB. 


\begin{tabular}{|c|c|c|c|c|}
\hline & \multicolumn{2}{|c|}{ Occasional player } & \multicolumn{2}{|c|}{ Problematic player } \\
\hline Medium & $\begin{array}{l}0.912(0.473- \\
1.761)\end{array}$ & $\begin{array}{l}0.786(0.393- \\
1.571)\end{array}$ & $\begin{array}{l}1.713(0.948- \\
3.094)\end{array}$ & $\begin{array}{l}1.788(0.943- \\
3.390)\end{array}$ \\
\hline High & $\begin{array}{l}2.477(1.043- \\
5.880)\end{array}$ & $\begin{array}{l}2.120(0.900- \\
5.374)\end{array}$ & $\begin{array}{l}2.958(1.234- \\
7.094)\end{array}$ & $\begin{array}{l}3.147(1.259- \\
7.870)\end{array}$ \\
\hline \multicolumn{5}{|c|}{ a Model1 unadjusted } \\
\hline \multicolumn{5}{|c|}{ b Model2 adjusted for all the variables in the table } \\
\hline \multicolumn{5}{|c|}{$\begin{array}{l}\text { * Income: "Low" means less than } 4999 \text { RMB; "Medium” means between } 5000 \text { to } 9999 \text { RMB; "High' } \\
\text { means more than } 10000 \text { RMB. }\end{array}$} \\
\hline
\end{tabular}

Table 4

Further analysis of the Correlation between Mahjong Characteristics and the Sociodemographic factors.

\begin{tabular}{|llll|}
\hline Response variable & Independent variable & P value & OR(95\% C.I.) \\
\hline Frequency & Age $(18-29 \mathrm{yrs})$ vs $(>=50 \mathrm{yrs})$ & $<.0 .001$ & $0.082(0.026-0.258)$ \\
\hline Duration & Age(30-49 yrs) vs $(>=50 \mathrm{yrs})$ & 0.001 & $0.258(0.12-0.554)$ \\
\hline Jetton & Jetton & 0.003 & $3.408(1.511-7.687)$ \\
\hline & Age(30-49 yrs) vs $(>=50 \mathrm{yrs})$ & 0.001 & $6.468(2.236-18.708)$ \\
\hline Quarrel with family & Monthly income & 0.032 & $2.004(1.064-3.774)$ \\
\hline & Motton & 0.001 & $3.625(1.750-7.508)$ \\
\hline
\end{tabular}

\section{Results}

\section{Socio-demographic characteristics}

This study recruited a total of 539 participants, including $223(41.37 \%)$ males and $316(58.63 \%)$ females. Of the participants, 151 (28.01\%) had played Mahjong and $388(71.99 \%)$ had not played Mahjong. Among the participants, $83.67 \%$ are over 30 years old, $89.42 \%$ have below university level of education, and $86.46 \%$ are married.

\section{Mahjong playing behaviors}

As shown in Table 2, of the 151 subjects who played Mahjong, 76 were occational players, 75 were problematic players, The land-lost peasants who played Mahjong more than three times per week 
accounted for $27.8 \%$ of all the players. The duration of each time was longer than three hours among $83.4 \%$ of the players. Approximately $60 \%$ of Mahjong players chose to stake more than five Chinese RMB in one game. More than half (56.3\%) chose to play in Mahjong parlors. Approximately one in five individuals $(22.5 \%)$ chose to play in their own home or a friend's house. Nearly all (96.0\%) of the participants reported eating regularly while playing Mahjong, with most $(90.0 \%)$ taking meals at their homes or their friend's houses. $87.4 \%$ of the participants reported incidents of smoking while playing Mahjong. 23.2\% of them admitted to having quarrels with family members regarding playing Mahjong. Almost all participants reported that their friends or relatives also play Mahjong. Moreover, a substantial proportion of land-lost peasants (25.8\%) had experienced some physical discomfort, such as lumbago and shoulder pain, as a result of their Mahjong playing behaviors. However, the participants also believe they benefit from playing Mahjong, in ways, such as making friendly contacts (32.2\%), eliminating negative emotions (24.3\%), and engaging in a positive mental exercise (15.1\%). Considering that this research uses a convenient sampling method, these frequency results are not representative of the whole land-lost peasants and may reflect some problems.

\section{Influencing factors of Mahjong playing behaviors}

As shown in Table 3, the influencing factors of playing Mahjong were analyzed via a multivariate analysis using a multinominal logistic regression model of subgroups determined by demographic factors, such as gender, age, education level, and monthly income. The significant sociodemographic factors influencing Mahjong playing behaviors are described below. Comparing land-lost peasants who are middle-aged (30-49 years old) and young people (18-29 years old), the RRRs were $5.782(95 \% \mathrm{Cl}$ 1.589-21.038) for problematic Mahjong playing. Moreover, comparing the land-lost peasants who are elderly ( $>=50$ years old) and young (18-29 years old), the RRRs were $5.036(95 \% \mathrm{Cl} 1.265-20.054)$ for problematic Mahjong playing. Comparing high and low monthly incomes, the RRRs were 3.147 (95\% Cl 1.259-7.870) for problematic Mahjong playing. Comparing occasional Mahjong playing between "junior and senior" and lower education, the interaction between education and Mahjong playing behaviors failed to reach a significance level $(p=0.073)$. In this study, "junior and senior" refers to junior high school and high school. Gender and marital status are not statistically significant in this study.

\section{Discussion}

We have several interesting findings on the sociodemographic factors affecting Mahjong playing behaviors. One of the most important conclusions is that the age of land-lost peasants has a significant association with Mahjong playing behaviors. The results show that the middle-aged and elderly are extremely prone to be problematic Mahjong players when compared with young people (18-29 years old) with the RRRs reaching 5.782 and 5.036, respectively. Among them, those who are in their fifties or above have the highest frequency of playing Mahjong. The elderly do not engage in important labor after entering old age; have more vacant time; and entail that they feel lonely, depressed, or empty frequently. Some scholars also confirmed that the elderly land-lost peasants need strong spiritual comfort due to their complex situation (Hang 2016; Teh and Tey 2019). We hypothesize that the elderly are often 
involved in Mahjong in search of spiritual comfort and social connection rather than being pathological gambling as their Mahjong bets are usually smaller than those of the younger players with an OR of 0.155 , and more than half of our participants admitted that Mahjong helped them build a social network and provided them with spiritual comfort. Also, one study demonstrate that gamblers aged 60 years and older had significantly lower odds of having pathological gambling than those in the younger age group $(\mathrm{OR}=0.4)($ Subramaniam et al. 2015).

The middle-aged are usually the economic cornerstones of the family, especially for land-lost peasants. Thus, they are under great pressure to support their families due to urbanization. Their Mahjong bet is also bigger than that of the younger and older players. This finding may indicate that the middle-aged participants regard Mahjong as a gambling project, and they want to win money or chase losses instead of playing just for entertainment. Our study also found that the bet level had a significant positive association with family disputes possibly because individuals who become addicted to Mahjong may neglect their responsibilities to school, work, childrearing, and family commitments (Blaszczynski et al., 1998; Zheng et al., 2010). Hence, a middle-aged player becoming addicted to Mahjong will cause a family crisis as he does not work hard and even loses money because of gambling(Subramaniam et al. 2017). At the same time, a study in Singapore (Subramaniam et al., 2015) reported that middle-aged people has significantly high rates of pathological gambling. The analysis results in our study show that land-lost peasants who play Mahjong with high stakes are likely to play for a long duration and the frequency of Mahjong is positively correlated with the stake, which suggests a pathological addiction to Mahjong in this population. This result may be the case because the winner wants to win more, whereas the loser does not want to lose in gambling. This finding also reminds us that we should be aware of the Mahjong gambling problem in this population.

Our survey found that people with high monthly incomes are more likely to be problematic Mahjong players compared with those with low monthly incomes. This finding may be attributed to the fact that they have more free time and experience less pressure to support their families. On the contrary, Mahjong participants with low monthly incomes have to face the pressure of supporting their families and are likely to quarrel with their family if they ignore this responsibility, so they do not have the time to play Mahjong. Moreover, those with a high monthly income may play Mahjong in a "small" bet and just play for entertainment. However, in the context of this study, the bet of those with a high monthly income was considered "large". Such inconsistency is also a flaw in this research. In any case, monthly income affects land-lost peasants' Mahjong playing behaviors, and the association between monthly income and Mahjong playing behaviors need further exploration.

Furthermore, our results also show that playing Mahjong has both positive and negative impacts on the participants. On the negative side, a quarter of the land-lost peasants played Mahjong more than three times per week, and nearly three quarters of the land-lost peasants spent three to six hours playing Mahjong in one sitting. On average, each session of play lasted 4.5 hours, which is similar to the results 
found in a Chinese-Australian community in Sydney (Zheng et al., 2010). With such a long duration of play, the participants are prone to suffer from hemorrhoids, prostatitis, lumbar muscle strain, or cervical spondylosis (Hui-qing et al., 2011). A previous study (Subramaniam et al., 2015) also argues that Mahjong participation can increase an elderly player's blood pressure and heart rate. Moreover, $87.4 \%$ of the land-lost peasants reported that people were smoking during Mahjong. According to earlier research, smoking rates in Mahjong rooms are as high as 51.33\% (Jin-xiang et al., 2012), and exposure to smoking environments increases the risks of respiratory and cardiovascular diseases (Yang et al., 2013; Brokenleg et al., 2014). These results reflect that Mahjong is a recreational activity that is typically engaged in at a high frequency and for a long duration within an enclosed, smoky environment. As such, Mahjong participation carries substantial hazards to a player's health (Stillman et al., 2007).

On its positive side, land-lost peasants may also benefit from playing Mahjong. According to our research, Mahjong participants believe that they can make friendly contacts or eliminate negative emotions by playing(Keovisai and Kim 2019; Teh and Tey 2019). Previous investigations (Ross and Zhang, 2008; Cheng et al., 2006, 2012) confirmed that playing Mahjong has significant negative associations with distress and dementia. Research originating in the Netherlands showed that migrants may benefit from favorable socioeconomic, public health, and health-care conditions (Mackenbach et al., 2005). We also firmly believe that Mahjong can help land-lost peasants to build a social network, provide them with spiritual comfort, and ultimately integrate them into a new environment(Keovisai and Kim 2019). Measures should be taken to make Mahjong a form of entertainment rather than of gambling and reduce the adverse effects of Mahjong playing behaviors on the players' health. Mahjong and its associated playing behaviors can be improved in many ways. Participants can reduce their playing duration and take enough breaks to help avoid being sedentary. In addition, the Mahjong room can post a "no smoking" notice, which has been confirmed effective in reducing smoking rates(Jin-xiang et al., 2012), and add a ventilation system. Lastly, the stakes can be regulated as it has a significant positive association with Mahjong playing duration. Controlling the stake can help decrease the risk of Mahjong gambling problems.

\section{Limitations}

This study still have several potential limitations. First, only 539 participants were investigated out of the large number of land-lost peasants. Second, the participants were recruited by convenience sampling and represented mainly the middle-aged and elderly of the community. Thus, the data may be subject to selection bias. Third, the self-report questionnaire lacks validity and reliability analysis, which limit the indepth understanding of Mahjong playing behaviors. Fourth, this research work is a cross-sectional study that cannot confirm the causal relationship between Mahjong playing behavior and the related variables.

\section{Conclusion}


As most land-lost peasants were middle-aged, had a lower educational level, and had to care for family members on a tight income, this population group seemed to face more substantial challenges in life than the urban residents. Mahjong participation carries potential risks to the players' health and may have significant negative effects on their lives. We have discovered that age and monthly income are crucial factors affecting the Mahjong playing behaviors of land-lost peasants. In addition, although playing Mahjong is harmful to health, it can help immigrants adapt to the new environment. This study represents one of the first efforts to examine the relationship between Mahjong playing behaviors and health among land-lost peasants in China. When properly utilized, the results from this study may help promote the integration of land-lost peasants into the urban environment and improve their health conditions.

\section{References}

1 J Mou, SM Griffiths, H Fong, MG Dawes. (2013). Health of China's rural-urban migrants and their families: a review of literature from 2000 to 2012. Br Med Bull, 106, 19-43. doi: 10.1093/bmb/ldt016

22018 Revision of World Urbanization Prospects [cited 201820 October]. . 2018 Revision of World Urbanization Prospects [cited 201820 October]. Available. URL. https://population.un.org/wup/. [20 December 2018]

3 L Hong, Y Ling-yun. (2010). [Chongqing Household Registration Reform and Its Revelation for the Zhejiang Province]. City(12), 58-60

$4 \mathrm{~J} \mathrm{Li}, \mathrm{N}$ Rose. (2017). Urban social exclusion and mental health of China's rural-urban migrants - A review and call for research. HEALTH PLACE, 48, 20-30. doi: 10.1016/j.healthplace.2017.08.009

5 BL Zhong, TB Liu, SSM Chan, D Jin, CY Hu, J Dai, HFK Chiu. (2018). Common mental health problems in rural-to-urban migrant workers in Shenzhen, China: prevalence and risk factors. EPIDEMIOL PSYCH SCI, 27(03), 256-265. doi: 10.1017/S2045796016001141

6 R Wang, Z Chen, Y Zhou, L Shen, Z Zhang, X Wu. (2019). Melancholy or mahjong? Diversity, frequency, type, and rural-urban divide of social participation and depression in middle- and old-aged Chinese: A fixed-effects analysis. Social science \& medicine (1982), 238, 112518. doi:

10.1016/j.socscimed.2019.112518

7 Y Li. (2013). Understanding health constraints among rural-to-urban migrants in China. QUAL HEALTH RES, 23(11), 1459-1469. doi: 10.1177/1049732313507500

8 S Ebrahim, S Kinra, L Bowen, E Andersen, Y Ben-Shlomo, T Lyngdoh, L Ramakrishnan, RC Ahuja, P Joshi, SM Das, M Mohan, SG Davey, D Prabhakaran, KS Reddy. (2010). The effect of rural-to-urban migration on obesity and diabetes in India: a cross-sectional study. PLOS MED, 7(4), e1000268. doi: 10.1371/journal.pmed.1000268 
9 X Du, A Patel, CS Anderson, J Dong, C Ma. (2019). Epidemiology of Cardiovascular Disease in China and Opportunities for Improvement: JACC International. J AM COLL CARDIOL, 73(24), 3135-3147. doi: 10.1016/j.jacc.2019.04.036

10 WY Zheng, M Walker, A Blaszczynski. (2010). Mahjong gambling in the Chinese-Australian community in Sydney: a prevalence study. J GAMBL STUD, 26(3), 441-454. doi: 10.1007/s10899-009-9159-3

11 ST Cheng, AC Chan, EC Yu. (2006). An exploratory study of the effect of mahjong on the cognitive functioning of persons with dementia. Int J Geriatr Psychiatry, 21(7), 611-617. doi: 10.1002/gps.1531

12 ST Cheng, PK Chow, EC Yu, AC Chan. (2012). Leisure activities alleviate depressive symptoms in nursing home residents with very mild or mild dementia. Am J Geriatr Psychiatry, 20(10), 904-908. doi: 10.1097/JGP.0b013e3182423988

13 ATC Lee, M Richards, WC Chan, HFK Chiu, RSY Lee, LCW Lam. (2018). Association of Daily Intellectual Activities With Lower Risk of Incident Dementia Among Older Chinese Adults. JAMA PSYCHIAT, 75(7), 697-703. doi: 10.1001/jamapsychiatry.2018.0657

14 CE Ross, W Zhang. (2008). Education and psychological distress among older Chinese. J AGING HEALTH, 20(3), 273-289. doi: 10.1177/0898264308315428

15 JKL Teh, NP Tey. (2019). Effects of selected leisure activities on preventing loneliness among older Chinese. SSM - population health, 9, 100479. doi: 10.1016/j.ssmph.2019.100479

16 L Jin-xiang, W Yun-jun, S Yan, Z Jian-jun, K Fan-xiang. (2012). [Mahjong room hygiene survey and evaluation of intervention effects]. Chinese Journal of Disease Control \& Prevention, 16(05), 411-416

17 M Keovisai, W Kim. (2019). "It's Not Officially Gambling": Gambling Perceptions and Behaviors Among Older Chinese Immigrants. J GAMBL STUD, 35(4), 1317-1330. doi: 10.1007/s10899-019-09841-4

18 Z Hang. (2016). [Case Study on the Mental Consolation of the Elderly in Rural Areas--Taking Shanbei Village, Tianyu Town, Ji'an City as an Example]. Thesis, Jinggangshan University.

19 M Subramaniam, E Abdin, S Shahwan, JA Vaingankar, L Picco, CJ Browning, SA Thomas, SA Chong. (2015). Culture and age influences upon gambling and problem gambling. Addictive behaviors reports, 1 , 57-63. doi: 10.1016/j.abrep.2015.04.004

20 A Blaszczynski, S Huynh, VJ Dumlao, E Farrell. (1998). Problem Gambling Within a Chinese Speaking Community. J GAMBL STUD, 14(4), 359-380

21 M Subramaniam, SA Chong, P Satghare, CJ Browning, S Thomas. (2017). Gambling and family: A two-way relationship. J BEHAV ADDICT, 6(4), 689-698. doi: 10.1556/2006.6.2017.082 
22 M Subramaniam, E Abdin, S Shahwan, JA Vaingankar, L Picco, CJ Browning, SA Thomas, SA Chong. (2015). Culture and age influences upon gambling and problem gambling. Addict Behav Rep, 1, 57-63. doi: 10.1016/j.abrep.2015.04.004

23 L Hui-qing, C Xiang-rong, C Shen, W De-sheng, Z Yan. (2011). [Epidemiological investigation on cervical spondylosis among mahjong enthusiasts in Huamu community of Shanghai]. Shanghai Journal of Preventive Medicine, 23(09), 461-462

24 G Yang, Y Wang, Y Zeng, GF Gao, X Liang, M Zhou, X Wan, S Yu, Y Jiang, M Naghavi, T Vos, H Wang, AD Lopez, CJ Murray. (2013). Rapid health transition in China, 1990-2010: findings from the Global Burden of Disease Study 2010. LANCET, 381(9882), 1987-2015. doi: 10.1016/S0140-6736(13)61097-1

25 IS Brokenleg, TK Barber, NL Bennett, BS Peart, BJV Blue. (2014). Gambling with our health: smoke-free policy would not reduce tribal casino patronage. AM J PREV MED, 47(3), 290-299. doi:

10.1016/j.amepre.2014.04.006

26 F Stillman, A Navas-Acien, J Ma, S Ma, E Avila-Tang, P Breysse, G Yang, J Samet. (2007). Second-hand tobacco smoke in public places in urban and rural China. TOB CONTROL, 16(4), 229-234. doi:

$10.1136 /$ tc. 2006.018333

27 JP Mackenbach, V Bos, MJ Garssen, AE Kunst. (2005). [Mortality among non-western migrants in The Netherlands]. Ned Tijdschr Geneeskd, 149(17), 917-923

\section{Declarations}

\section{Ethics approval and consent to participate}

The study was reviewed and approved by the Institutional Review Board of Chongqing Medical University. All participants provided verbal consent, participating in this study was associated with minimal risk, and non-biological samples were collected.

\section{Consent for publication}

Not applicable

\section{Availability of data and material}

Data available on request

Competing interests

No conflict of interest exits in the submission of this manuscript.

\section{Funding}


Xintu Center for Community Health Promotion, Shanghang, China (X7681).

\section{Authors' contributions}

Design and implementation: $H Z$, YZ. Writing the paper and revision: $H Z, X Y X, Y Z, F Z, N C Z, S S, Z M S$.

\section{Acknowledgments}

Not applicable 